\title{
Produção de enzimas celulíticas de Trichoderma reesei por fermentação em estado sólido e sua aplicação na hidrólise enzimática de biomassa
}

\author{
J. M. GASPAROTTO ${ }^{1}$; L. B. WERLE ${ }^{2}$; M. A. MAINARDI ${ }^{2}$; M. A. MAZUTTI ${ }^{3}$; S. L. \\ $\mathrm{JAHN}^{4}$ \\ ${ }^{1}$ Universidade Federal do Rio Grande do Sul, Pós graduação em Engenharia de Química \\ ${ }^{2}$ Universidade Federal de Santa Maria, Curso de Engenharia Química \\ ${ }^{3}$ Universidade Federal de Santa Maria, Departamento de Engenharia Química \\ E-mail para contato: jmgasparotto@gmail.com
}

\begin{abstract}
RESUMO - Neste trabalho, foram estudadas as melhores condições de processo para produção de enzimas celulolíticas por Trichoderma reesei NRRL6153 por fermentação em estado sólido de resíduos agroindustriais, e a aplicação do extrato enzimático produzido na hidrólise de bagaço de cana-de-açúcar. Os experimentos de produção foram avaliados em frascos cônicos e validados em um biorreator de leito fixo. As condições otimizadas para a produção de celulases em escala de bancada foram: $68,6 \%$ de umidade, $0,9 \%$ de farelo de soja, $15 \%$ de água de maceração e milho e quatro dias de fermentação, a $28{ }^{\circ} \mathrm{C}$. O extrato enzimático bruto obtido foi aplicado para a hidrólise do bagaço de cana in natura em banho de água com e sem ultrassom, sendo obtidos 229,0 e 224 g. $\mathrm{kg}^{-1}$, respectivamente, a $43,4{ }^{\circ} \mathrm{C}$ e $18,6 \%$ de extrato enzimático, com razão sólido/líquido igual a 0,15 e quatro horas de reação. Os rendimentos obtidos são comparáveis às enzimas comerciais, indicando que as enzimas celulolíticas de Trichoderma reesei podem ser uma boa alternativa para a sacarificação de material lignocelulósico residual.
\end{abstract}

\section{INTRODUÇÃO}

Grandes esforços vêm sendo realizados por pesquisadores com o intuito de encontrar rotas tecnológicas para a reutilização e conversão de resíduos agroindustriais lignocelulósicos em produtos de interesse comercial. Dentre as principais fontes destes resíduos, encontramos o bagaço de cana-de-açúcar, o qual apresenta um enorme potencial para a obtenção de produtos de interesse industrial como bioetanol, glicose e biomassa proteica, uma vez que o mesmo é renovável e apresenta-se em grandes quantidades (OJUMU et al., 2003).

É necessário o processamento da matéria prima lignocelulósica para a conversão em açúcares simples como glicose, celobiose, xilose e vários outros, normalmente expressos em termos de açúcares totais (REGULY, 1996 e GLAZER e NIKAIDO, 2007). Dentre essas etapas de processamento encontra-se de hidrólise que pode ser realizada principalmente por via ácida ou enzimática. A sacarificação enzimática vem sendo, em muitos casos, preferida por oferecer um potencial de redução de custos em longo prazo. Isso porque o emprego de enzimas em processos industriais muitas vezes utiliza condições mais brandas de 
processamento e ao mesmo tempo, oferece um aumento da especificidade da reação e da pureza do produto, além de reduzir o impacto ambiental (CHERRY e FIDANTSEF, 2003).

Porém, os custos de produção destas enzimas ainda são muito altos. No âmbito de produção de etanol a partir de materiais lignocelulósicos, por exemplo, as celulases são insumos que impactam significativamente o processo, e, segundo Zhuang et al. (2007), podem representar até $18 \%$ do custo operacional de uma planta de hidrólise enzimática. Assim, é de extrema importância o desenvolvimento de novas rotas tecnológicas para a produção dessa enzima com custos mais baixos.

A fermentação em estado sólido (FES) para a produção de enzimas celulíticas tem sido bastante estudada na tentativa de contornar este problema. Neste processo, o crescimento microbiano ocorre na ausência de água livre, sendo mais indicado para o cultivo de fungos e leveduras que bactérias. Algumas vantagens que se destacam na FES são: A natureza dos substratos utilizados como suporte, fonte indutora ou de carbono na produção da enzima, que podem ser resíduos lignocelulósicos, por exemplo, bem como o menor volume de reação necessário, o que leva à necessidade de utilização de biorreatores menores e, consequentemente, de menor custo (SCHMIDELL e FACCIOTTI, 2001).

Os principais produtores de enzimas celulíticas são os micro-organismos, sendo que apresentam destaque entre eles os fungos filamentosos pelo fato de secretarem grandes quantidades de diferentes enzimas. Esse conjunto de enzimas promove uma sinergia no processo de hidrólise de material celulósico, tendo assim, motivado a sua ampla utilização para a produção de enzimas industriais. Entre as espécies de fungos filamentosos mais estudadas, encontram-se os gêneros Penicillium sp., Humicola sp., Trichoderma sp., Fusarium sp., Aspergillus sp., entre outros. (RABELO, 2007).

É necessário otimizar as condições de hidrólise das celulases produzidas anteriormente para conseguir o funcionamento satisfatório dos processos de sacarificação (RABELO, 2007). Nesse sentido, algumas tecnologias emergentes, como o pré-tratamento ou hidrólise assistida por ultrassom, vêm sendo utilizadas com intuito de melhorar a eficiência do processo e, bons resultados vem sendo alcançados (LEÃES et. al, 2013).

Nesse contexto, o presente trabalho tem por objetivo otimizar a produção de enzimas celulíticas de T. Reesei por FES em substrato de bagaço de cana-de-açúcar e suplementos, além de otimizar a hidrólise do bagaço in natura utilizando extrato enzimático bruto, com e sem o uso de ultrassom.

\section{MATERIAIS E MÉTODOS}

\subsection{Microorganismos, meio de cultura e substrato sólido.}

\subsubsection{Microorganismo}

As cepas de Trichoderma reesei NRRL - 6156 foram obtidas no Serviço de Pesquisa Agrícola (ARS Culture Collection), do Departamento de Agricultura dos Estados Unidos.

\subsubsection{Meio de cultura e Pré-inóculo}


A cultura estoque de $T$. reesei foi propagada utilizando o meio de cultura Ágar/batata/dextrose (meio PDA). Após ser devidamente autoclavado a $121 \pm 1^{\circ} \mathrm{C}$ durante 30 minutos, o meio de cultura foi vertido em placas de Petri e, quando frio, pequenas porções de microorganismo foram inoculadas na superfície das placas. Em seguida, as mesmas foram transferidas para um estufa microbiológica com temperatura controlada a $28 \pm 1^{\circ} \mathrm{C}$ durante 5 dias.

Para o preparo do pré-inóculo, os conídios das culturas esporuladas nas placas foram suspensos em $5 \mathrm{~mL}$ de água estéril pelo método de raspagem. Então, $5 \mathrm{~mL}$ da suspensão foi transferido para um Erlenmeyer contendo $50 \mathrm{~mL}$ de meio de cultura líquido com composição previamente estabelecida (em g.L ${ }^{-1}: 2,0$ de $\left(\mathrm{NH}_{4}\right)_{2} \mathrm{SO}_{4}, 0,5$ de $\mathrm{MgSO}_{4}, 1,0$ de $\mathrm{FeSO}_{4} .7 \mathrm{H}_{2} \mathrm{O}$, 1,0 de $\mathrm{MnSO}_{4} .7 \mathrm{H}_{2} \mathrm{O}$, 10,0 de extrato de levedura, 10,0 de glicose, 150,0 de água de maceração de milho, e 1,0 mL.L ${ }^{-1}$ de Tween 80), e este foi incubado num agitador orbital durante 2 dias a $28 \pm 1^{\circ} \mathrm{C}$ e $120 \mathrm{rpm}$. Todas as condições experimentais foram definidas com base em pesquisa bibliográfica e testes preliminares.

\subsubsection{Substrato sólido}

O bagaço de cana foi obtido em uma microdestilaria localizada na Universidade Federal de Santa Maria. No laboratório, o mesmo foi processado até um tamanho de partícula final de 8 mesh. O substrato sólido para a produção da enzima foi composto por bagaço de cana como fonte de carbono principal, suplementadas com farelo de soja e água de maceração de milho.

\subsection{Produção de enzimas celulolíticas}

$\mathrm{Na}$ primeira etapa trabalho, as fermentações foram realizadas em frascos contendo $5 \mathrm{~g}$ de substrato sólido. Posteriormente, o substrato sólido foi suplementado e o teor de umidade ajustado a nível especificado. Cada frasco foi coberto com algodão hidrofóbico e adequadamente autoclavado a $121 \pm 1^{\circ} \mathrm{C}$ durante 30 minutos. Após arrefecimento, em cada balão foi inoculado a quantidade definida no planejamento experimental e os frascos foram incubados durante $96 \mathrm{~h}$ em estufa microbiológica com controle de temperatura e umidade.

Ensaios preliminares foram realizados para uma varredura das variáveis importantes na produção de celulases por fermentação em estado sólido. Com base na análise dos resultados preliminares, um planejamento composto central rotacional (CCRD) para duas variáveis independentes foi realizado para investigar a influência do teor de umidade (65 a 90\%) e da concentração de farelo de soja (0-5,9\% em peso) sobre a produção de enzimas celulolíticas. Foram avaliadas como respostas a atividade em papel de filtro (FPU.g ${ }^{-1}$ ), atividade de exocelulases $\left(\mathrm{Ug}^{-1}\right)$, atividade de endocelulases $\left(\mathrm{Ug}^{-1}\right)$ e atividade de xilanases $\left(\mathrm{Ug}^{-1}\right)$. Além das atividades enzimáticas, o rendimento em açúcares fermentescíveis na hidrólise in situ também foi determinado. As condições otimizadas obtidas no CCRD foram reproduzidas para avaliar a produção de enzimas celulolíticas em um biorreator de leito fixo com aeração forçada usando uma carga de $70 \mathrm{~g}$ de substrato seco.

\subsection{Extração das enzimas celulolíticas}

Ao final de cada fermentação, as enzimas celulolíticas foram extraídas com $100 \mathrm{~mL}$ de tampão $50 \mathrm{mM}$ de acetato de sódio / ácido acético (pH 4,8) em um agitador orbital a 120 rpm 
e $28 \pm 1{ }^{\circ} \mathrm{C}$ durante 1 hora. Em seguida, $30 \mathrm{~mL}$ do extrato enzimático foi retirado para as determinações analíticas de atividade e outros $70 \mathrm{~mL}$ foram mantidos no recipiente com sólido fermentado durante 4 horas em um banho termostático com agitação a $50{ }^{\circ} \mathrm{C}$ para avaliar o rendimento em açúcares fermentescíveis obtido para a hidrólise enzimática in situ. As atividades das enzimas celulolíticas foram determinadas como descrito por Ghose (1987), com algumas modificações.

\subsection{Hidrólise de bagaço de cana-de-açúcar assistida por ultrassom usando extrato bruto de enzimas celulolíticas}

As enzimas celulolíticas utilizadas para os experimentos que envolvem a hidrólise de bagaço de cana-de-açúcar assistida por ultrassom foram produzidos no biorreator de leito fixo. Após a fermentação, as enzimas foram extraídas de acordo com a metodologia descrita anteriormente e o extrato bruto foi mantido sob refrigeração $\left(4^{\circ} \mathrm{C}\right)$, até o momento dos testes.

Hidrólises foram realizadas num banho de ultrassom (Unique Inc., modelo USC 1800A, Brasil, BR), equipado com um transdutor com vibrações longitudinais e controle de temperatura (precisão de temperatura de $\pm 1,0{ }^{\circ} \mathrm{C}$ ). A unidade de ultrassom tem uma frequência de operação de $40 \mathrm{kHz}$ e uma potência elétrica máxima classificada de $132 \mathrm{~W}$.

Os efeitos da temperatura $\left(40,0-63,4{ }^{\circ} \mathrm{C}\right)$ e concentração do extrato enzimático (10 $20 \%$ ) na hidrólise do bagaço de cana-de-açúcar foram avaliados por meio de um novo CCRD com oito experimentos e mais três pontos centrais. Todos os ensaios foram realizados utilizando $15 \mathrm{~g}$ de bagaço de cana-de-açúcar e um volume final de $100 \mathrm{~mL}$ (razão sólido/líquido $=0,15)$ de tampão de acetato de sódio/ácido acético $0,1 \mathrm{M}(\mathrm{pH} 4,8)$, durante 4 horas. Os experimentos foram realizados em um banho de água simples e com banho de água com ultrassom. Os resultados foram expressos em termos de gramas de açúcares fermentescíveis por quilograma de material sólido seco, determinado pelo método de DNS (Miller , 1959). Todas as análises foram feitas em triplicata e as médias foram expressas como resposta.

\subsection{Análise dos resultados estatísticos}

Todos os resultados foram analisados usando o software Statistica ${ }^{\circledR} 7.0$ (Statsoft Inc., Tulsa, OK, USA), considerando um nível de significância de $90 \%$.

\section{RESULTADOS E DISCUÇÃO}

\subsection{Produção de enzimas celulíticas}

A Tabela 1 apresenta as atividades das enzimas celulíticas e também o rendimento de açúcares fermentescíveis para os 11 experimentos do CCRD. A atividade em papel filtro (FPA) variou de 0,61 (exp. 6) até 3,25 FPU.g ${ }^{-1}$ (exp. 7); a atividade exocelulases variou de 0,22 (exp. 3) até 6,38 U.g (exp. 10); a atividade de xilanases variou de 127,86 (exp. 4) até $366,81 \mathrm{U}^{-1} \mathrm{~g}^{-1}$ (exp. 6); e a atividade da endocelulases variou de 0,28 (exp. 4 e 7) até 4,14 U.g ${ }^{-1}$ (exp.3). 
Tabela 1 - Matriz da CCRD para avaliar a influência das variáveis independentes na produção de enzimas celulíticas por FES

\begin{tabular}{llllllll}
\hline & \multicolumn{6}{l}{ Variáveis Dependentes } & \multicolumn{6}{c}{ Variáveis independentes } \\
\hline Exp. & $\begin{array}{l}\text { Farelo de soja } \\
(\mathbf{m} / \mathbf{m}, \boldsymbol{\%})\end{array}$ & $\begin{array}{l}\text { Umidade } \\
(\mathbf{m} / \mathbf{m}, \boldsymbol{\%})\end{array}$ & $\mathbf{R 1}$ & $\mathbf{R 2}$ & $\mathbf{R 3}$ & $\mathbf{R 4}$ & $\mathbf{R 5}$ \\
$\mathbf{1}$ & $0,9(-1)$ & $68,6(-1)$ & 1,42 & 3,13 & 170,73 & 2,09 & 47,3 \\
$\mathbf{2}$ & $5,0(1)$ & $68,6(-1)$ & 1,31 & 2,13 & 172,60 & 0,95 & 46,6 \\
$\mathbf{3}$ & $0,9(-1)$ & $81,9(1)$ & 1,31 & 0,22 & 184,53 & 4,14 & 33,8 \\
$\mathbf{4}$ & $5,0(1)$ & $81,9(1)$ & 0,68 & 5,03 & 127,86 & 0,28 & 28,7 \\
$\mathbf{5}$ & $0,0(-1,41)$ & $75,3(0)$ & 0,92 & 5,37 & 153,96 & 1,16 & 44,0 \\
$\mathbf{6}$ & $5,9(1,41)$ & $75,3(0)$ & 0,61 & 1,12 & 366,81 & 2,13 & 29,1 \\
$\mathbf{7}$ & $2,9(0)$ & $65,0(-1,41)$ & 3,25 & 6,26 & 167,75 & 0,28 & 44,6 \\
$\mathbf{8}$ & $2,9(0)$ & $90,0(1,41)$ & 1,21 & 3,58 & 128,61 & 1,31 & 23,3 \\
$\mathbf{9}$ & $2,9(0)$ & $75,3(0)$ & 1,21 & 5,26 & 145,38 & 2,07 & 36,0 \\
$\mathbf{1 0}$ & $2,9(0)$ & $75,3(0)$ & 1,21 & 6,38 & 148,37 & 1,16 & 44,0 \\
$\mathbf{1 1}$ & $2,9(0)$ & $75,3(0)$ & 1,04 & 5,26 & 134,57 & 2,44 & 41,8 \\
\hline
\end{tabular}

$\mathrm{R} 1=$ Atividade em papel filtro $\left(\mathrm{U} \cdot \mathrm{g}^{-1}\right) ; \mathrm{R} 2=$ atividade de exocelulases $\left(\mathrm{U} \cdot \mathrm{g}^{-1}\right) ; \mathrm{R} 3=$ Atividade de xilanases $\left(\mathrm{U} \cdot \mathrm{g}^{-}\right.$ $\left.{ }^{1}\right) ; \mathrm{R} 4=$ atividade de endocelulases $\left(\mathrm{U}_{\mathrm{g}} \mathrm{g}^{-1}\right) ; \mathrm{R} 5=$ Açúcares fermentescíveis $\left(\mathrm{g} \cdot \mathrm{kg}^{-1}\right)$

Os dados da Tabela 1 foram usados para determinar os efeitos das variáveis independentes nos resultados obtidos considerando um nível de significância de $90 \%(\mathrm{p}<0,1)$. De modo geral, efeitos lineares e quadráticos para o conteúdo de umidade foram significantes para a atividade em papel filtro. Para as outras enzimas não foi verificado influência das variáveis independentes, indicando que independente das condições experimentais usadas o aumento das enzimas produzidas é estatisticamente o mesmo.

Um aspecto positivo observado foi a produção de todos os tipos de enzimas, isso é importante pelo fato de que uma reação eficiente de hidrólise enzimática de material lignocelulósico depende do efeito sinérgico de todas as enzimas. Porém, é difícil selecionar uma condição experimental para maximizar a produção de todas as enzimas. Por essa razão, a condição experimental ótima para aumento de escala foi obtida analisando a produtividade de açúcares fermentáveis obtidos através da hidrólise in situ. Através dos dados da Tabela 1, verifica-se que a quantidade de açúcares produzidos variou de 23,3 (exp. 8) até 47,3 g. $\mathrm{kg}^{-1}$ (exp. 1).

Os dados referentes à hidrólise in situ foram usados para determinar o efeito das variáveis estudadas. Os resultados obtidos mostraram que efeitos lineares tanto para umidade quanto para a concentração de farelo de soja foram estatisticamente significativos $(\mathrm{p}<0,1)$ para a produção de açúcar. Também, verificou-se que o aumento da umidade e concentração de farelo de soja diminui o efeito sinérgico da hidrólise enzimática.

Com o intuito de otimizar as condições experimentais para obter uma máxima produção de açúcares fermentescíveis, um modelo considerando uma significância de $p<0,1$ foi proposto como mostra a equação 1 .

$$
F S=40,58-3,36 \cdot S B-7,7 \cdot M
$$


Onde: $\mathrm{FS}=$ Açúcares fermentescíveis produzidos $\left(\mathrm{g} \cdot \mathrm{kg}^{-1}\right), \mathrm{SB}=$ Farelo de soja e $\mathrm{M}=$ umidade.

O modelo da Equação 1 foi validado por análise de variância (ANOVA) e a determinação do coeficiente $\left(\mathrm{R}^{2}\right)$ dos dados experimentais ajustados pelo modelo, que foi de 0,8651 , podendo-se concluir que o ajuste foi satisfatório. A condição do experimento 1 foi considerada ótima pelo melhor ajuste e reprodução dos dados. Suas condições experimentais para a produção de enzimas celulíticas $(68,6 \%$ em peso de umidade e $0,9 \%$ em peso de farelo de soja) foram utilizados no aumento de escala em um biorreator com aeração forçada. Um total de $70 \mathrm{~g}$ de substrato foram utilizados. A atividade de todas as enzimas obtidas no experimento foram

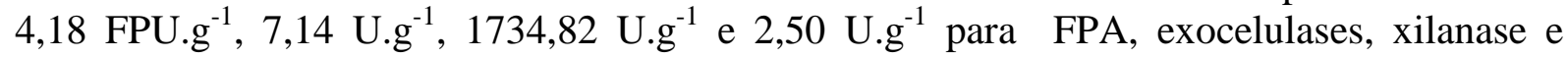
endocelulases, respectivamente. Os resultados obtidos foram melhores do que os obtidos em escala de bancada, e isso pode ser explicado pelo fato de que a configuração do biorreator e leito fixo com aeração forcada apresenta melhor transferência de calor e massa que o erlenmeyer usado na etapa anterior ao aumento de escala.

\subsection{Aplicação do extrato enzimático para a hidrólise do bagaço de cana-de- açúcar.}

O extrato enzimático produzido no aumento de escala anterior foi usado para otimizar a hidrólise do bagaço de cana-de-açúcar em um reator de banho de água (WB) e em banho de ultrassom (US). As variáveis independentes estudadas foram temperatura e extrato enzimático. Os resultados obtidos no CCRD referentes ao rendimento da hidrólise enzimática são apresentados na Tabela 2. O rendimento da hidrólise variou de 80 até $224 \mathrm{~g}^{\mathrm{kg}} \mathrm{kg}^{-1}$ para a hidrólise realizada em WB e variou de 102 até $229 \mathrm{~g} . \mathrm{kg}^{-1}$ para hidrólise em US.

Tabela 2 - Matriz do CCRD para avaliar a influência das variáveis independentes na hidrólise enzimática do bagaço de cana-de-açúcar em WB e US usando o extrato de enzimas celulíticas obtidos por FES.

\begin{tabular}{cccccc}
\hline EXP & T( $\left.{ }^{\circ} \mathbf{C}\right)$ & EE (\% v/v) & $\begin{array}{c}\text { Rend. em WB } \\
\left(\mathbf{g . k g}^{-1}\right)\end{array}$ & $\begin{array}{c}\text { Rend. em US } \\
\left(\mathbf{g . k g}^{-1}\right)\end{array}$ & $\begin{array}{c}\text { Aumento/diminuição } \\
\text { do rend. (\%) }\end{array}$ \\
\hline 1 & $43,4(-1)$ & $11,45(-1)$ & 199,0 & 209,0 & 5,0 \\
2 & $60,0(1)$ & $11,45(-1)$ & 122,0 & 147,0 & 21,0 \\
3 & $43,4(-1)$ & $18,55(1)$ & 224,0 & 229,0 & 2,0 \\
4 & $60,0(1)$ & $18,55(1)$ & 128,0 & 191,0 & 49,0 \\
5 & $40(-1,41)$ & $15(0)$ & 150,0 & 157,0 & 4,0 \\
6 & $63,4(1,41)$ & $15(0)$ & 80,0 & 102,0 & 28,0 \\
7 & $51,7(0)$ & $10(-1,41)$ & 187,0 & 178,0 & $-4,0$ \\
8 & $51,7(0)$ & $20(1,41)$ & 211,0 & 221,0 & 5,0 \\
9 & $51,7(0)$ & $15(0)$ & 174,0 & 201,0 & 16,0 \\
10 & $51,7(0)$ & $15(0)$ & 184,0 & 192,0 & 4,0 \\
11 & $51,7(0)$ & $15(0)$ & 184,0 & 191,0 & 4,0 \\
\hline
\end{tabular}

O rendimento mais elevado em WB foi de $224,0 \mathrm{~g} \cdot \mathrm{kg}^{-1}$ nas condições do exp. 3 ( $\mathrm{T}=$ $43,4{ }^{\circ} \mathrm{C} ; \mathrm{EE}=18,6 \%$, v/v). Para as condições experimentais do exp. $1\left(\mathrm{~T}=43,4{ }^{\circ} \mathrm{C} ; \mathrm{EE}=\right.$ $11,5 \%$, v/v), o rendimento de hidrólise foi $199,0 \mathrm{~g} . \mathrm{kg}^{-1}$ usando $38 \%$ menos extrato enzimático em comparação com exp. 3. Resultado parecido foi visualizado para a hidrólise em US, para os experimentos 1 e 3, obtendo-se 209 g. $\mathrm{kg}^{-1}$ e 229,0 g. $\mathrm{kg}^{-1}$. 
De modo geral, observou-se um discreto aumento na eficiência de hidrólise com a ação do ultrassom, mas este aumento foi mais expressivo para $\mathrm{T}>60^{\circ} \mathrm{C}$. $\mathrm{O}$ mesmo comportamento foi observado para Leães (2013).

Com base na análise estatística dos parâmetros do modelo e dos dados da Tabela 2, dois modelos empíricos são apresentados abaixo. Eq. 2 apresenta os termos significativos $(p<0,1)$ sobre o teor de hidrólise na água do banho, e Eq. 3 representa o rendimento obtido no banho de ultrassom:

$$
\begin{gathered}
\text { Rendimento }_{W B}=180,62-34,06 \cdot T-30,14 \cdot T^{2}+12,11 . E E^{2} \\
\text { Rendimento }_{U S}=203,87-22,26 \cdot T-28,16 \cdot T^{2}++15,63 \cdot E E^{2}
\end{gathered}
$$

Onde: WB e US representam banho de água e reator de ultrassom, o rendimento para cada um dos reatores está expresso em gramas de açúcar por $\mathrm{kg}$ de bagaço de cana-de-açúcar $\left(\mathrm{g} . \mathrm{kg}^{-1}\right)$, T é a temperatura e EE é a concentração de extrato enzimático.

O efeito negativo da temperatura sobre o rendimento de ambos os modelos está relacionada com a desativação de enzimas em altas temperaturas. Já o termo referente ao extrato enzimático é positivo porque sempre que sua concentração aumentar aumentará a produção de açúcares uma vez que os mesmo são os catalisadores da reação.

Estes modelos foram validados por análise de variância (ANOVA). O teste $\mathrm{F}$ foi realizado para os dois casos, sendo obtidos, respectivamente, valores de 8,0 e 3,2 vezes maior do que os tabelados para significância de $\mathrm{p}=0,1$, e os coeficientes de determinação $\left(\mathrm{R}^{2}\right)$ foram 0,9462 e 0,8594, respectivamente. Mostrou-se assim, que os modelos são satisfatórios para os dois sistemas.

Através dos modelos pode-se verificar que as melhores condições experimentais é realmente o experimento 1 , com condições de $\mathrm{T}=43,4{ }^{\circ} \mathrm{C}$ e $\mathrm{EE}=18,6 \%$, para ambos os sistemas WB e US.

\section{CONSIDERAÇÕES FINAIS}

Os resultados obtidos neste trabalho permitiram concluir que o teor de umidade ideal e concentração de farelo de soja para a produção de enzimas celulolíticas por fermentação em estado sólido foram 68,6\% (m/m) e 0,9\% (m/m), respectivamente. Além disso, 99,1\% (m/m) de bagaço de cana-de-açúcar, $15 \%$ de água de maceração de milho, 0,5 ml de inoculo por grama de substrato a $28 \pm 1{ }^{\circ} \mathrm{C}$ e 4 dias de fermentação mostrou-se a melhor condição obtida para a produção de celulases. Após a definição da condição operacional, a produção foi realizada num biorreator de leito fixo, aumentando a produção de todas as enzimas determinadas. O extrato bruto enzimático foi aplicado para a hidrólise do bagaço de cana-de-açúcar em água e banho de ultrassom, sendo obtidos 224,0 e 229 g. $\mathrm{kg}^{-1}$ respectivamente, à temperatura de $43,4{ }^{\circ} \mathrm{C}$ e a concentração de extrato enzimático de 18,6 \%. Os rendimentos de hidrólise obtidos são comparáveis às enzimas comerciais, e que permite a conclusão de que a utilização de extrato bruto de celulases de $T$. reesei na sacarificação de bagaço de cana-de-açúcar, sem qualquer prétratamento pode ser uma alternativa viável para reduzir os custos do processo de hidrólise. 


\section{REFERÊNCIAS}

CHERRY, J. R.; FIDANTSEF, A. F. Directed evolution of industrial enzymes: an update. Current Opinion in Biotechnology, vol. 14, p. 438-443, Aug. 2003.

GLAZER, A.N; NIKAIDO, H. Microbial Biotechnology: Fundamentals of applied microbiology. $2^{\text {a }}$ Ed., New York: Editora Cambridge University Press, 2007.

GHOSE, T. K.,. Measurement of cellulase activities. Pure App. Chem. v. 59, pag. 257-268, 1987.

LEÃES, E. X.; ZIMMERMANN, E.; SOUZA, M.; RAMON, A. P.; MEZADRI, E. T.; DAL PRÁ, V.; TERRA, L. M.; MAZUTTI, M. A. Ultrasound-assisted enzymatic hydrolysis of cassava waste to obtain fermentable sugars. Biosystems Engineering, vol. 115, p. 1-6, 2013.

MILLER, G.L., Use of dinitrosalicylic acid and reagent for determination of reducing sugar. Anal. Chem. v. 31, pag. 426-427, 1959.

OJUMU, T. V.; SOLOMON, B. O.; BETIKU, E.; LAYOKUN, S. K.; AMIGUN, B. Cellulase Production by Aspergillus flavus Linn Isolate NSPR 101 fermented in sawdust, bagasse and corncob. African Journal of Biotechnology, vol. 2, n. 6, p. 150-152, Jun. 2003.

RABELO, S. C. Avaliação de desempenho do pré-tratamento com peróxido de hidrogênio alcalino para a hidrólise enzimática de bagaço de cana-de-açúcar. 2007. Dissertação (Mestrado em Engenharia Química). Universidade Estadual de Campinas. Campinas, 2007.

REGULY, J.C. Biotecnologia dos processos fermentativos. Pelotas: Editora e Gráfica Universitária UFPEL, v. 1, 1996.

SCHMIDELL, W. , FACCIOTTI, M.C.R. Biorreatores e Processos Fermentativos. Edgard Blücher Ltda., vol.2, p.179-190, 2001.

ZHUANG, J.; MARCHANT, M. A.; NOKES, S. E.; STROBEL, H. J. Economic analysis of cellulase production methods for bioethanol. Applied Engineering in Agriculture, vol. 23, p. 679687, 2007. 